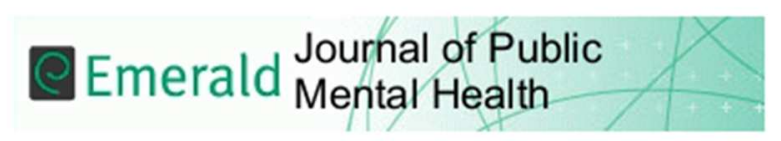

\title{
The Influence of Therapeutic Horticulture on Social Integration
}

\begin{tabular}{|r|l|}
\hline Journal: & Journal of Public Mental Health \\
\hline Manuscript ID & JPMH-12-2015-0050.R1 \\
\hline Manuscript Type: & Original Research Paper \\
\hline Keywords: & $\begin{array}{l}\text { therapeutic horticulture, qualitative, social inclusion, person centred, public } \\
\text { mental health }\end{array}$ \\
\hline \multicolumn{2}{|l}{} \\
\hline
\end{tabular}

SCHOLARONE

Manuscripts 


\title{
Title: The Influence of Therapeutic Horticulture on Social Integration
}

\begin{abstract}
Study Purpose: The purpose of the pilot study was to qualitatively evaluate the impact of therapeutic horticulture on social integration for people who have mental health problems.

Method: A qualitative grounded theory approach captured the perceptions about therapeutic horticulture from people with mental health problems. Data were collected using semistructured focus group and interviews from a purposive sample $(n=7)$ and were analysed using a constant comparative approach.

Findings: Four key themes emerged from the analysis: 'A Space to Grow', 'Seeing the Person', 'Learning about Each Other through Nature' and 'Connecting to Nature and Others'. The findings suggest that therapeutic horticulture enabled participants to integrate socially, engage with nature and develop confidence.
\end{abstract}

Social Implications: Therapeutic horticulture embody the principles of empowerment, person centeredness and can support people with mental health problems to integrate socially.

Originality: There is limited evidence about the influence that therapeutic horticulture have on mental health and social integration. The use of therapeutic horticulture is an area that is gathering evidence and this small study highlights the perceived potential benefits of this approach.

Declaration of interest: None

Key words: therapeutic horticulture, social inclusion, public mental health and well being 


\section{Introduction:}

The World Health Organisation (WHO 2001) predicted that mental health problems such as depression will become a major strain on services by 2020. Therapeutic Horticulture (TH) is a nature based approach that can promote wellbeing for people with mental health problems through using a range of green activities such as gardening and contact with animals. Gonalez et al (2010) report that TH can be used to promote health and well-being for people who are socially excluded, hence it is acknowledged that therapeutic horticulture can provide effective support for people with mental illness in the community (DH 2004). TH has been promoted globally to help people engage with gardening or other environmental activities to improve social inclusion, for example, in Nordic countries, the government implemented a 'Green Care' National Policy (Sempik et al 2010), which uses green therapies such as therapeutic horticulture to reduce anxiety. The increased use of $\mathrm{TH}$ has generated global interest and in 2007, the UK national charity 'Mind' set out the green agenda for mental health and argued that this should be a clinically valid treatment for mental health distress.

\section{Background}

Interest in the relationship between nature and its positive benefits for humans has grown over the last 20 years. There is a developing evidence base about the effectiveness of TH and

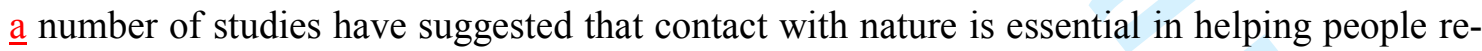
establish a sense of overall well-being (Fieldhouse 2003). It is believed that exposure to nature can have a positive effect on a person's mental well-being moreover, Gonzalez et al's (2010) prospective study of cohesiveness for people in a TH programme, found that it can be a beneficial supplementary intervention in clinical depression. Equally, it was reported by Van den Berg, (2010) and Mayer et al (2008) that exposure to nature can have a positive effect on a person's mental well-being; moreover, Gonzalez et al's (2010) prospective study 
of cohesiveness for people in a TH programme, found that it can be a beneficial supplementary intervention in clinical depression. However, it is unclear how this occurs in relation to the types of exposure to nature and Burls (2007) argued that there remains ambiguity as to the effectiveness of some models of ecotherapy, such as therapeutic horticulture. Moreover, Burls \& Caan (2005) note that working outdoors can help individuals $\underline{\text { to connect which subsequently can alleviate social isolation, but further research is needed to }}$ understand how this occurs in relation to the types of exposure to nature (Burls 2007). Hence, whilst the link between well-being and health is well established (Pretty, 2004), evidence about how TH approaches can support the rehabilitation of people in the community with common mental health problems is less well known.

Over the past decade, a number of social enterprises have emerged that provide therapeutic horticulture programmes for improving the well-being of local communities. The social enterprise approach builds on 'Social Firms' by facilitating people with mental health problems to develop new skills and re-engage with the workplace (Secker et al 2003). One social enterprise in the North West of England established a Garden Centre to support people with mental health problems. Their work included the use of therapeutic horticulture to encourage participants to sow, grow, care, cook and eat vegetables and work with others to become socially active. This research sought to qualitatively evaluate the impact of $\mathrm{TH}$ on social integration for service users with mental health problems through their experience at the Garden Centre.

\section{Study Purpose:}

The purpose of the pilot study was to qualitatively evaluate the impact of TH on social integration for people who have mental health problems. 


\section{Research Design}

A qualitative, grounded theory approach (Corbin \& Strauss, 2008) was used to capture the participants experiences of TH. The ontological position of constructivism is concerned with explicating subjective experiences from the social world through engaging with phenomena to construct meaning (Howarth 2012).

\section{Participants:}

Invariably, data are collected from a purposive sample until concept saturation is achieved; hence, the sample size in qualitative studies are small and dependent upon the point at which conceptual clarification is achieved (Draucker et al 2007). In total, 7 participants who had experience of volunteering at the Garden Centre volunteered. The ages of the participants ranged from 24 to 57, and there were four males and three females. The majority were either unemployed, or off work at the time of the interviews; two participants had experienced long term mental health problems, three had anxiety caused by work related stress and two suffered from moderate depression.

\section{Data Collection}

The majority of the volunteers took part in a focus group $(n=5)$; the remaining two participants were interviewed separately in face to face interviews. The questions were opened ended and asked participants about their experiences of $\mathrm{TH}$. The focus group and face-to-face interviews lasted between $30-45$ minutes and were conducted in a quiet room at the Garden Centre. The interviews were digitally recorded with consent and later transcribed verbatim.

Data Analysis 
A constant comparative analytic approach was used which involved reading and re-reading the interview transcripts (Corbin \& Strauss, 2008). This helped to identify open codes and invivo codes which were then axial coded to reveal commonalities and emerging themes. Consequently, the data were analysed contemporaneously during the semi-structured interviews and the focus group through which, key categories are developed and confirmed with the participants and research team (Corbin \& Strauss 2008).

\section{Ethics}

The project received ethical approval from the University Ethical Approval Panel. Participants were given the option to withdraw from the study and all data obtained was protected as per the UK Data Protection Act (1998).

\section{Findings}

Four key themes emerged; these included; a 'Space to Grow', 'Seeing the Person', 'Learning about Others through Nature' and 'Connecting to Nature and Others'. The findings suggest that TH enabled participants to integrate socially, engage with nature and develop confidence.

\section{Space to Grow:}

The 'Space to Grow' emerged as a theme and relates to the way in which participants described how TH promoted confidence which included connecting with others through shared green activities. For example;

“At one time I would have thought I can't do it, I can't show anybody, but now I feel that I can and I am quite happy to stand there and advise others, (P2). 
Participants felt proud of their achievements enjoyed being part of something that helped them to grow:

"And I like watching stuff grow. .... Think it makes you look forward....It is just something to look forward to as well, .... it gives you that enthusiasm to get up and go out I think. " P3

These findings suggest that $\mathrm{TH}$ supported the growth of confidence and enhanced a connection with the environment which provided a common sense of purpose.

\section{Seeing the Person}

Participating in TH appeared to engender confidence in some who were then able to talk about themselves. For some, this provided insight into the 'person' was relevant as many of the participants had suffered from the stigma associated with mental illness. One participant suggested;

"It is about seeing you as people, rather than you coming along with something (illness). You are an individual who likes gardening”. (P7)

For some, taking part with $\mathrm{TH}$ inspired them to leave their home because the work undertaken provided a sense of accomplishment:

"I mean, it feels nice, I feel like I have accomplished something. Because if I was at home, now, I wouldn't be dressed, I would be in pyjamas, just sat in" (P1)

The findings indicate that the $\mathrm{TH}$ facilitated a person centred approach which provided a shared activity and helped reduce social isolation.

Learning about Others through Nature 
The participants were encouraged to learn about nature using flexible approaches that enabled the participants to select activities from a schedule. This provided a space to meet others and learn about nature.

“The other aspect is we eat together, or if you don't want to you can eat alone. But, you know, I have discovered that, ....I could enjoy helping or making something to eat. (P4).

"Nice being out in the fresh air, meeting new people... you can be with other people or you can stay in one particular area, you can just wander about and do what you fancy doing really”. (P3).

Equally, connecting with nature and others through $\mathrm{TH}$ provided a flexible opportunity to engage with others through learning about nature and sharing a common understanding.

\section{Connecting to Nature and Others}

The supportive environment and common participation in $\mathrm{TH}$ encouraged some participants who had become socially isolated, to re-connect with others. For example:

"If I didn't have here I'd have stayed at home, I would have just been reclusive $\operatorname{again} . . . "(P 2)$

“It is just shifting your viewpoint, isn't it? .....you just think that is really refreshing”. (P4)

These findings illustrate how TH offered meaningful activities that provided an opportunity for participants to grow, learn and connect with each other. 


\section{Discussion}

These research findings contribute a new perspective to the evidence base that suggest TH can promote mental health through connecting with nature to engage with others. As found in this study, the social benefits of outdoor green activities can add to a sense of belonging which promotes health and well-being (Diamant \& Waterhouse; 2010). These findings dovetail with the concept of recovery as an approach which embodies the principles of empowerment, person centeredness and developing a positive identity (Rethink, 2009). It is thought that 'connectedness' to nature can positively effect a person's well-being (Mayer et al 2009), and it is this sense of well-being, engendered by TH that can influence a person's ability to cope with stressful life events and enhances positive mental health (Van de Berg et al., 2010). The social interaction associated with the use of green spaces can support neighbourhood and social networks that can contribute to a community feeling of security (Lee \& Maheswaran, 2010). A significant role for LA's, therefore, is to identify existing TH resources and capabilities through an assets based approach and work with NHS, social care and third sector partners to support access to and use of green spaces.

As found in this study, the social benefits of outdoor green activities can add to a sense of belonging which promotes health and well-being (Diamant \& Waterhouse; 2010, Rebeiro, 2001). Working outdoors and growing plants for oneself and others provided a space to grow and direction and space to meet others with similar interests and experiences. Research has demonstrated that access to $\mathrm{TH}$ can help people connect to nature and contribute to social cohesion through which positive messages about mental health can be heard (Burls et al 2010), however, longitudinal research that use quantitative health outcomes such as reduced $\underline{\text { GP attendance, reduction in depression and physical aspects such as obesity is also required }}$ to strengthen the evidence base (PHE 2014). Equally, TH needs to be promoted more widely 
amongst clinicians, practitioners and local authorities to influence how people use green spaces, as well as their access to leisure facilities (Buck \& Gregory 2013).

\section{Conclusion}

There is a need to ensure that public health agendas include initiatives that embrace the community and develop new ways in which to support this group of people. TH provides a person centred approach that enables people with mental health problems to re-engage and connect with their fellow human beings. Embedding TH within a social prescribing context to enable communities to benefit from $\mathrm{TH}$ maybe one solution as part of a focussed public health strategy to reduce social isolation, improve community cohesion and improve individuals physical and mental wellbeing.

\section{References}

Buck, D., Gregory, S. (2013), Improving the Public's Health. A Resource for Local Authorities, The Kings Fund, London.

Burls, A. (200714) _"People and green spaces: promoting public health and mental well-being

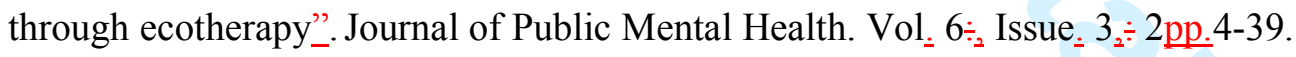

Burls, A., \& Caan, W. (2005), "Human health and nature conservation". British Medical Journal. 331: 1221- 2.

Burls, A., Luscombe, G., Millward, A. (2010), Discover Yourself Outside: New Landscapes for a Civil Society in a Changing Climate, UK MAB, Urban Forum.

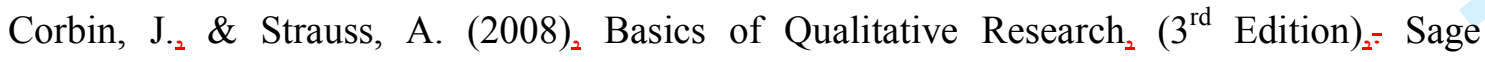
Publications $_{2} ;$ London. 
Department of Health. (2004)_-The Ten Essential Shared Capabilities- A Framework for the Whole of the Mental Health Workforce. Department of Health $\overline{\bar{g}}_{2}$ London.

Diamant, E., \& Waterhouse, A. (2010) ${ }_{2}$ "Gardening and Belonging: reflections on how social and therapeutic horticulture may facilitate health, wellbeing and inclusion". British Journal of Occupational Therapy $\overline{-}_{2} 73_{2}(2)$, pp. $84-88$.

Data Protection Act (1998) available from http://www.legislation.gov.uk/ukpga/1998/29/contents accessed 22nd July 2014.

Draucker, C.B., Martsolf, DS., Ross, R., \& and Rusk, TB-.(2007) ${ }_{2}{ }_{-}$Theoretical Sampling and Category Development in Grounded Theory", Qualitative Health Research $\bar{r}_{2}$ 17 $\div$ ․ pp. 11371148.

Fieldhouse, J. (2003) _ "The Impact of an Allotment Group on Mental Health Clients' Health, Wellbeing and Social Networking". British Journal of Occupational Therapy- ${ }_{2} 66_{2}$ (7) pp. 286-296.

Gonzalez, M. T., Hartig, T., Patil, G., Martinsen, E., \& and Kirkevold. (2010) _ “A prospective study if group cohesiveness in therapeutic horticulture for clinical depression". International Journal of Mental Health Nursing. $15 \div 2$ pp. $49-59$.

Howarth, M, L. (2012), Being Believed And Believing In: The Impact Of Delegitimation On Person- Centred Care For People With Chronic Back Pain. PhD Thesis:- University of Salford.

Lee, A., \& Maheswaran, R. (2010), "The health benefits of urban green spaces: A review of the evidence". Journal of Public Health, 33,(2),pp. 212-222. 
Mayer, F., S., Frantz, C., M., Bruehlman-Senecal, E., \& and Dolliver, K. (2009)=.2Why is nature beneficial? The role of connectedness to nature". Environment and Behaviour $_{2}=41_{2}(5)$, pp. 607-643.

MINDind (2007), Ecotherapy: The Green Agenda for Mental Health $\overline{-}_{2}$ Mind $_{2} ;$ London.

Public Health England. (2014), Local Action on Health Inequalities: Improving Access to Green Spaces, Health Equality Unit, UCL, Institute of Health Equalities.

Rebeiro, K. (2001), "Enabling occupation: The importance of an affirming environment", Canadian Journal of Occupational Therapy, 48, (8), pp. 697-707.

Rethink. (2009), 100 Ways to Support Recovery. A Guide for Mental Health Professionals. Rethink: $\dot{\overline{\%}}_{2}$ London.

Secker, J., Sandhya, S., \& and Grove, B. (2003), Developing social firms in the UK: A contribution to identifying good practice. Disability \& Society. $18 \div 5 \overline{-}_{2}$ pp. 659-674.

Sempik J., Hine, R.,E., \& and Wilcox, D. (2010), Green Care: A Conceptual Framework. A Report of the Working Group on the Health Benefits of Green Care $_{2} \cdot$ COST Action 866, Green Care in Agriculture, ISBN 978-1-907382-23-9,- Loughborough University UK.

$\underline{\text { Van den Berg, A., Maas, J., and Verhei, J. (2010), Green space as a buffer between stressful }}$ $\underline{\text { life events and health, Social Science Medicine, 70,(8), pp. 1203-10. }}$

World Health Organisation. (2001), World Health Report. World Health Organisation ${ }_{2} \dot{\bar{\xi}}$ Geneva. 